\title{
MODOS DE SUBJETIVAÇÃO DE JOVENS EM UM TERRITÓRIO DE
} CONFLITO SOCIOAMBIENTAL

\author{
MODOS DE SUBJETIVACION DE LOS JÓVENES EN UN TERRITORIO DE \\ CONFLICTO SOCIAL Y AMBIENTAL \\ FORMS OF SUBJECTIVIZATION OF YOUNG PEOPLE IN TERRITORY \\ WITH SOCIAL AND ENVIRONMENTAL CONFLICT
}

http://dx.doi.org/10.1590/1807-03102016v28n3p463

\author{
Rafael Prosdocimi Bacelar \\ Centro Universitário UNA, Belo Horizonte-MG e Faculdade Pitágoras, Betim/MG, Brasil \\ Lucia Rabello de Castro \\ Universidade Federal do Rio de Janeiro, Rio de Janeiro/RJ, Brasil
}

\begin{abstract}
RESUMO
A instalação de um grande empreendimento de mineração transformou a dinâmica social e ambiental na região próxima à Conceição do Mato Dentro, interior de Minas Gerais. A proposta extrativista alterou profundamente as relações históricas entre sujeitos, comunidades e territórios. A partir de uma pesquisa de orientação etnográfica analisamos como os jovens se subjetivam frente aos deslocamentos provocados na região. Os modos de subjetivação se constituem na configuração de formas de ser, sentir e agir frente às mudanças objetivas no território. Embora os jovens se queixem do empreendimento em razão dos problemas socioambientais causados, os mesmos reconhecem que a mineradora gerou o aumento de renda, a oferta de empregos e a promessa de desenvolvimento. Ao escutar as palavras dos jovens, vemos como eles são sujeitos que refletem e se posicionam frente aos conflitos em curso na região.
\end{abstract}

Palavras-chave: juventude; subjetivação, conflito; mineração; meio-ambiente.

\section{RESUMEN}

La instalación de un gran proyecto empresarial de minería transformó la dinámica social y ambiental en la región cercana al municipio de Conceição do Mato Dentro, en el interior del estado de Minas Gerais. La propuesta extractiva alteró profundamente las relaciones históricas entre los sujetos, comunidades y territorios. A través de una investigación de orientación etnográfica, analizamos como los jóvenes se subjetivan frente a los desplazamientos causados en la región. Los modos de subjetivación se constituyen en las configuraciones de las formas de ser, sentir y actuar frente a los cambios objetivos en el territorio. Mientras los jóvenes se quejan del proyecto debido a los problemas ambientales causados, ellos también reconocen que la minería ha generado aumento del ingreso, oferta de empleos y la promesa de desarrollo. Al escuchar las palabras de los jóvenes vemos como ellos son sujetos que reflexionan y se posicionan frente a los conflictos en curso en la región.

Palavras-clave: juventud; subjetivacion; conflito; mineria; ambiente.

\begin{abstract}
The installation of a big mining project transformed the social and environmental dynamics in the region around Conceição do Mato Dentro, Minas Gerais. The new enterprise "dislocated" the historical relations between individuals, communities and territories. From an ethnographic research orientation we have analyzed how young people subjectivate themselves when facing displacement caused in the region. The forms of subjectivization are established on the articulation between the objective changes and ways of interpretation of this process. While young people complain about the project due to various social and environmental problems, they recognize that the presence of mining has generated an increase in income and job opportunities, in addition to the promise of development. The words of young people show us how they are subjects that reflect and take decisions about the ongoing conflicts in the region.
\end{abstract}

Keywords: youth; subjectivization; conflict; mining; environment. 


\section{Introdução}

$\mathrm{Na}$ última década, diversos empreendimentos de extração mineral, produção agrícola e da geração de energia foram instalados no Brasil. Tais projetos se baseiam na exploração mercantil da natureza como meio de fomentar o crescimento econômico, o aumento de arrecadação e a ampliação de postos de empregos no país. As frutas e os vegetais, a terra, as águas e os minerais se tornam objetos de interesse do Estado e de grandes corporações que transformam tais bens em commodities, itens destinados à troca comercial (Coelho, 2015). A exploração capitalista do ambiente impõe o valor econômico aos bens de um território marcado por uma pluralidade de usos e significações (Acselrad, 2004).

Entendemos que a forma de utilização e de representação da natureza é parte de um modo de ser de uma comunidade, portanto, a instalação de novas formas de exploração mercantil do ambiente se traduz em alterações profundas na relação entre sujeito, comunidade e território. A intensificação da exploração das commodities, em especial com a extração mineral, causa a proliferação de conflitos socioambientais (Coelho, 2015; Zhouri \& Laschefski, 2010). O conflito entre modos de utilização da natureza se mostra também uma disputa simbólica sobre as funções das comunidades e dos lugares, um conflito entre diferentes universos de sentido (Rancière, 1996). Acselrad (2004, p. 35) lembra que "a água dos rios pode ter distintos usos: pode ser meio de subsistência de pescadores ribeirinhos ou instrumento de produção de energia barata para firmas eletro-intensivas". Povos indígenas, comunidades ribeirinhas e quilombolas, dentre outros grupos tradicionais, estão entre aqueles atores que por meio de lutas e embates questionam a suposta legitimidade do modelo capitalista de apropriação do ambiente (Zhouri \& Laschefski, 2010)

Se há um debate a respeito dos modelos de apropriação do ambiente e sobre as diferentes propostas de desenvolvimento, poucas pesquisas analisam os processos de subjetivação implicados na forma como as pessoas se posicionam, resistem ou integram-se às novas situações. Com este trabalho, nos unimos a outras pesquisas que refletem sobre os elementos psicossociais atrelados aos conflitos socioambientais em curso no Brasil contemporâneo (Jerônimo \& Souza, 2015; Mataresi, 2012). Neste artigo, especificamente, analisamos os modos de subjetivação de jovens que vivem em um contexto de conflito socioambiental decorrente da instalação de um projeto de mineração no interior de Minas Gerais (Bacelar, 2014).

\section{"Projeto Minas-Rio": conflito e deslocamento}

O chamado "Sistema Minas-Rio" é um empreendimento de extração de minério de ferro composto por três grandes estruturas: a mina, localizada na Serra da Ferrugem em Conceição do Mato Dentro (CMD); o mineroduto, que consiste em grandes dutos pelos quais o minério é escoado até o litoral do Rio de Janeiro; e o Porto de Açu, por intermédio do qual o minério de ferro é exportado para o mercado chinês. $\mathrm{Na}$ realização desta pesquisa focamos nos efeitos provocados na área próxima à mina, portanto não analisamos os processos ligados ao mineroduto e ao porto. O empreendimento de propriedade da companhia multinacional Anglo American ${ }^{l}$ extrai toneladas de minério de ferro da Serra da Ferrugem e, por meio do bombeamento de água, leva o produto até o Porto de Açu, em São João da Barra - norte fluminense (Becker \& Pereira, 2011; Diversus, 2011; SISEMA, 2008).

Nesta pesquisa analisamos os modos de subjetivação dos jovens de uma região de Minas Gerais que, até o início dos anos 2000, era reconhecida pelas belezas naturais e pela história colonial. Subitamente, CMD e os municípios vizinhos - Alvorada de Minas e Dom Joaquim - se tornaram cenário de uma transformação sem precedentes, causada pela construção de um dos maiores empreendimentos minerários do país. Utilizamos a noção de deslocamento para compreender os efeitos desencadeados pela chegada da "Minas-Rio" na região. O deslocamento se traduz por um processo profundo de transformação das relações, de desarticulação de posições historicamente fixadas entre sujeitos, culturas e território (Laclau, 1993, pp. 58-60; Norval, 2007). Para Laclau (1993), o deslocamento gera a desestabilização da posição do sujeito na relação com a estrutura social que lhe garantia suporte. Assim, o deslocamento gera a fragmentação da estrutura social e retira as bases de sustentação de um modo de ser, ver e agir (Glynos \& Howarth, 2007; Laclau, 1993). Com essa noção abordamos as mudanças materiais e simbólicas causadas pelo projeto "Minas-Rio" sobre práticas, lugares e comunidades, focando nas transformações sobre os modos de subjetivação articulados a esse processo. Embora marcado pela negatividade, o deslocamento é também meio para a construção de novas estruturas sociais e configurações subjetivas.

Pensemos nos efeitos "deslocatórios" na vida dos trabalhadores do capitalismo em seu nascimento. Eles são bem conhecidos: a dissolução das comunidades tradicionais, a disciplina severa e extenuante das fábricas, os baixos salários, a insegurança do emprego. Porém esta é apenas uma parte dos efeitos. Porque a resposta dos operários à deslocação de suas 
formas de vida pelo capitalismo não foi se submeter passivamente aos diktats deste último, mas romper máquinas, organizar sindicatos, realizar greves. E neste processo, novos conhecimentos, novas habilidades necessariamente surgiam, o que de outro modo não haveria acontecido. (Laclau, 1993, pp. 5556)

A extração mineral é uma atividade reconhecida pelo forte impacto social e ambiental no território onde ela se instala. Para possibilitar a exploração do minério de ferro, o curso de rios é alterado, comunidades são extintas e milhares de trabalhadores migram buscando empregos (Coelho, 2015; Zhouri \& Laschefski, 2010). A situação observada na área de entorno da mina na Serra da Ferrugem e nas cidades próximas ao "MinasRio" revela o impacto desse processo sobre a dinâmica econômica, social e cultural da região (Diversus, 2011; Galdino, 2013).

Para parte dos moradores locais, o novo ciclo de mineração será favorável a todos os habitantes, mas principalmente para as gerações mais novas, pelo surgimento de novos campos de trabalho e de formação profissional. A criação de cursos profissionalizantes e a oferta de empregos no empreendimento da Anglo American alimentam o sonho dos moradores por um futuro de prosperidade e "desenvolvimento", termo este que passou a figurar nos diálogos cotidianos da região. Por outro lado, não são poucos aqueles que, preocupados com a degradação ambiental e o aumento de violência e da criminalidade, temem pela qualidade de vida na região e enfatizam os problemas e riscos, sobretudo para as crianças e os jovens. Embora sintam de perto os efeitos e a tensão do processo, as novas gerações dificilmente são convocadas a se expressar publicamente sobre o que pensam ou a participar efetivamente nas deliberações de suas comunidades. Para muitos, as perspectivas dos jovens estariam contidas nas falas dos adultos: seus pais, professores, agentes públicos e funcionários das empresas. No entanto, entendemos que os jovens do $\underline{\text { MatoDentro }}^{2}$ não irão apenas aproveitar ou sofrer passivamente com o que acontece; eles são atores que ativamente sentem, refletem e se posicionam acerca dos conflitos que se desdobram no cenário local. O questionamento sobre os modos de subjetivação dos jovens parte da visão de que, para além de se falar sobre os jovens, é preciso escutar, realmente, o que eles dizem (Castro, 2011).

\section{A participação dos jovens sobre o destino das sociedades}

A participação dos jovens no mundo público se tornou um tema de inúmeras pesquisas, nas últimas décadas, que abordam tanto as possibilidades de ação política como as restrições ao engajamento dos jovens sobre os destinos da sociedade (Castro, 2001a, 2011; Ibase \& Polis, 2007; Rattansi \& Phoenix, 1997). Analisando a posição dos jovens na sociedade contemporânea, Castro (2001a) questiona por qual razão os jovens são continuamente deslegitimados como sujeitos com poder de ação sobre os rumos da sociedade contemporânea. Para a autora, a participação social dos jovens - entendida aqui em sentido amplo - é inibida por diferentes razões, tanto jurídicas como culturais. A exclusão das novas gerações sobre a responsabilidade pelo destino do mundo comum oculta que essas já são, de fato, partícipes das relações que definem nossas comunidades. Os jovens por vezes se sentem perplexos por não saberem como agir, mas não deixam de se envolver com o mundo que os cerca. "Como moradores das cidades, crianças e jovens entram em contato com as desigualdades sociais, e como cidadãos que aprendem sobre suas responsabilidades sociais, vêem-se demandados a compreender melhor o mundo em que vivem e como transformá-lo" (Castro, 2001b, p. 125).

É recorrente que crianças e jovens apareçam nos discursos que vigoram no MatoDentro para representar expectativas e medos em relação ao futuro da região. Escutamos de muitos homens e mulheres ao longo da permanência em campo as perguntas: "Será que meus filhos e netos vão viver aqui? Será que a vida deles será melhor?”. O jovem como metáfora em relação ao futuro enlaça o tempo presente ao porvir e assim empresta sua face à dinâmica dos acontecimentos. No entanto, a persistência de tal noção por vezes esmaece a realidade presente dos jovens, ao enfatizar não suas experiências atuais, mas o que está por vir (Castro, 2001a). Em nossa pesquisa, focamos na forma como os jovens vivem o turbulento presente no MatoDentro, sendo que o futuro importa como elemento que incide sobre o tempo corrente. Interrogamos sobre os efeitos provocados pela construção da mina em questão buscando compreender os modos de subjetivação dos jovens nesse processo: como falam, observam, sentem e se posicionam em meio a tantas dificuldades e possibilidades. Se muito é dito pelos adultos sobre o que é melhor para os jovens no MatoDentro, procuramos com esta pesquisa investigar como esses atores falam e o que pensam sobre as mudanças no contexto local. Ao interrogar sobre a maneira como os jovens se posicionam, nos distanciamos da perspectiva do jovem como objeto para aproximarmos deles como sujeitos (Castro, 2001a). 


\section{Considerações metodológicas}

Para apreender os modos de subjetivação de jovens em um cenário marcado por tensão e problemas diversos foi fundamental refletir continuamente sobre as escolhas metodológicas. Partimos de uma perspectiva qualitativa, pois nosso objetivo com a realização desta pesquisa foi compreender os efeitos subjetivos de mudanças sociais, econômicas e culturais (Minayo, 2012, p. 623). Com essa proposta, o problema metodológico se traduziu na busca por meios de acessar a perspectiva dos sujeitos pesquisados, os jovens, levando em consideração a situação de conflitos e seus efeitos sobre a relação pesquisador-pesquisados. Assim, as disputas materiais e simbólicas em curso no MatoDentro geraram desconfianças por parte dos nativos em relação aos pesquisadores que, tais como a Anglo American, chegaram da cidade grande falando de mineração, desenvolvimento, trabalho, futuro. Uma "anedota" do campo de pesquisa exemplifica tais interrogações. Um grupo de alunos em uma escola do município de Dom Joaquim se aproximou de um dos pesquisadores para uma conversa em grupo. Ao descerem uma escada, sem perceber que eram ouvidos, os jovens falavam com a vice-diretora sobre a conversa que teriam com o pesquisador. Em certo momento umas das jovens perguntou à vice-diretora da escola: "É pra falar bem ou pode falar mal?". A moça estava preocupada com a posição que deveria assumir frente ao pesquisador, como deveria proceder, qual opinião ela deveria expressar a respeito da mineração. A desconfiança transparecia de diferentes formas, em comentários maliciosos, em recusas, em questionamentos acerca dos nossos objetivos. A permanência em campo por sete meses, a participação em diferentes âmbitos da sociedade local, a clara independência em relação à empresa mineradora e o apoio de atores chaves das comunidades foram meios para enfrentar tais desconfianças.

A tradição de um ecletismo metodológico da Psicologia Social crítica pode ser entendida como uma orientação guiada mais pela complexidade do objeto de pesquisa do que pela referência exclusiva às normatizações disciplinares. Assim, o caráter radicalmente descentrado e interdisciplinar da Psicologia Social se revela também nas escolhas metodológicas, definidas a partir da abordagem a um dado processo psicossocial (Alvaro \& Garrido, 2006; Narita, 2006). Ao considerar a melhor maneira de abordar os modos de subjetivação dos jovens no MatoDentro, entendemos que a reflexão etnográfica forneceu sustentação para uma compreensão mais abrangente de aspectos epistemológicos, éticos e políticos da pesquisa: a tensão entre as diferenças culturais e simbólicas entre pesquisador e sujeitos pesquisados, a situação de conflito, o questionamento da ilusão de uma realidade transparente e acessível ao observador (Geertz, 2012; Goldman, 2006; Peirano, 1995). A etnografia é um recurso valioso quando se trata de entender um processo psicossocial, considerando os determinantes econômicos, culturais e políticos (Sato \& Souza, 2001). É importante frisar que a busca pela referência na etnografia toma como pressuposto a existência de certa opacidade entre a perspectiva do pesquisador e a cultura local, o que demanda atenção e aproximação do tempo-espaço da cultura pesquisada.

Ao contrário da adoção de uma metodologia previamente estabelecida, em nossa pesquisa decidimos as estratégias a cada momento, de acordo com as possibilidades no campo de pesquisa (Sato \& Souza, 2001). Portanto, a utilização de diferentes instrumentos na presente pesquisa (observação, entrevista, roda de conversa e leitura crítica de documentos) se justificou com o objetivo de compreender os múltiplos aspectos que envolviam a vida dos jovens no "MatoDentro". Assim, as observações cotidianas registradas no diário de campo facilitavam o trabalho de construção do roteiro das entrevistas e oficinas. A circulação pela cidade e pelos distritos nos colocou em diferentes posições no cenário de pesquisa, o que também possibilitava uma compreensão multifacetada do processo.

O principal recurso metodológico da presente pesquisa, que teve uma função de guia sobre os outros métodos, foi a observação da realidade local e o registro no diário de campo. A partir das observações e dos diálogos sobre os efeitos do empreendimento na região de CMD tomamos decisões a respeito dos caminhos ulteriores da pesquisa. O diário é composto por observações, pequenas entrevistas e relatos de reuniões públicas. Outro método utilizado foi a realização de entrevistas com atores locais: diretores e coordenadores de escolas, referências comunitárias, ambientalistas e jovens. Entretanto, ainda que a confluência dos métodos descritos anteriormente nos permitisse construir um entendimento sobre o que transcorria, os modos de subjetivação dos jovens no território em conflito ainda permaneciam pouco claros. Com o propósito específico de observar a construção de posições singulares dos jovens em relação ao cenário, realizamos "rodas de conversa", técnica baseada nas oficinas e grupos de reflexão (Mattos, 2011).

Os grupos de reflexão podem ser utilizados como um método qualitativo e participativo que permite uma densa interação entre pesquisador e participantes da pesquisa, e evita a situação objetivante de mera "coleta de dados" para a pesquisa. A troca, o diálogo, a possibilidade de ir e vir na discussão do 
grupo, permitindo que diferentes falas se articulem e se contraponham, é marca dessa modalidade metodológica. (Mattos, 2011, p.132)

Com as "rodas de conversa" foi possível observar o posicionamento dos jovens em relação aos processos que os afetavam. Foram realizadas onze "rodas de conversa" em três escolas diferentes, sempre com alunos do ensino médio. Utilizamos pequenas narrativas ficcionais que dramatizavam aspectos da realidade na região para disparar o debate entre os jovens nas escolas. Dessa forma, discutimos situações envolvendo os empregos e o aumento de renda, a sensação de medo e insegurança, as questões afetivas e sexuais, a degradação ambiental, entre outras.

As entrevistas e as rodas de conversa com os jovens foram gravadas e transcritas. $\mathrm{O}$ diário de campo já foi registrado em formato digital, o que facilitou o procedimento de análise. A partir da leitura exaustiva de todo o material, buscamos compreender a junção dos efeitos de "deslocamento" apontados pelos moradores da região com os modos de subjetivação dos jovens, ou seja, as formas de ver, ser e agir. Ao verificar a pertinência de determinadas construções, estabelecemos categorias para o entendimento dos modos de subjetivação dos jovens do MatoDentro. Em um primeiro momento estabelecemos categorias bem amplas como: "efeitos positivos do projeto 'MinasRio'; "efeitos negativos do projeto 'Minas-Rio",, "visão do desenvolvimento e do progresso". A partir daí algumas subcategorias ganharam força, revelando aspectos singulares dos modos de subjetivação dos jovens.

\section{Discussão dos resultados: os modos de subjetivação dos jovens no Matodentro}

A instalação do projeto Minas-Rio deflagrou uma crise social ampla, com a desarticulação das funções e das práticas culturais do lugar. Alguns moradores afirmam que a região perdeu sua identidade. Outros, por sua vez, dizem que Conceição agora é uma cidade pequena com problemas de cidade grande. Ambos são modos de nomear o deslocamento provocado pela nova regência do território, tentativas de conferir sentido ao processo em curso. Os jovens da região observam as mudanças: com curiosidade veem o trânsito de camionetes e pessoas pelas estradas de chão; em casa escutam conversas sobre empregos e oportunidades; por amigos são informados de problemas com algumas famílias pela posse das terras; vez ou outra algum professor em sala de aula fala sobre os problemas da mineração. Ora, e o que eles pensam desses fatores? Como se posicionam em relação aos acontecimentos? O que querem?

Dividimos a pluralidade de posições encontradas entre as narrativas dos jovens do MatoDentro em três categorias de análise: a sensação de invasão causada pela presença de trabalhadores na região; a degradação dos rios e da natureza; as possibilidades de formação profissional e trabalho.

\section{Trabalhadores e estrangeiros: "um monte de gente esquisita"}

No diálogo com os jovens, era recorrente a queixa pela presença intensiva de homens "estranhos" nas cidades. Com a grande oferta de trabalho, em especial para a construção do empreendimento e das estruturas necessárias para sua operação, Conceição do Mato Dentro se tornou destino de milhares de trabalhadores, sendo esse um aspecto comum na atividade extrativista mineral (Coelho, 2015). Os trabalhadores chegaram ocupando os postos de trabalho, como também as casas, pousadas e hotéis criados para sustentar o turismo na bela região ${ }^{3}$ Em 2010, após a consecução da licença de instalação (LI) do projeto, foram construídos grandes alojamentos próximos à mina para receber parte dos trabalhadores do "Minas-Rio". Os alojamentos, situados às margens da rodovia MG-010, tornaram-se objeto de queixas tanto dos moradores como de funcionários do projeto. Estes reclamavam do regime de trabalho, da máqualidade da alimentação e da dificuldade no acesso a serviços diversos, demandas que suscitaram algumas greves entre os trabalhadores (Galdino, 2013). A situação se mostrou mais preocupante quando, em outubro de 2013, trabalhadores de uma empresa contratada pela Anglo American foram encontrados em regime análogo à escravidão (Rezende, 2013). Já os moradores nas imediações dos alojamentos reclamavam das brigas, do aumento dos acidentes nas estradas e do constrangimento das crianças e mulheres pela presença desses operários. Em Itapanhoacanga, distrito de Alvorada de Minas, uma jovem conta o que observou:

Tipo aqui em Itapanhoacanga, há cinco anos atrás aqui era uma paz. Ai, chegou primeiro aqui a Geosol [empresa especializada em perfuração de solos], aqui virou um inferno. Aquele monte de gente na rua, eu lembro que eu vinha aqui só pra passear, que eu morava fora, não conhecia mais ninguém aqui. Tem um monte de gente "esquisita", ai que veio o roubo das igrejas; sabe Deus quem é, gente daqui que não é, nunca aconteceu. Ai a gente fica toda insegura em relação a isso. (Entrevista realizada no dia $27 \mathrm{de}$ outubro, 2012) 
O envolvimento sexual dos homens com as mulheres da região é um dos fatores que mais geram queixas em relação à presença dos trabalhadores (Pedrosa, Grossi, \& Ariadne, 2013). A mudança demográfica gerada com a presença dos trabalhadores, em sua maioria homens, produziu efeitos difusos no campo das relações afetivas e sexuais. Em uma roda de conversa realizada com alunos do ensino médio em CMD, duas jovens oriundas do distrito de São Sebastião do Bom Sucesso, região próxima à mina, reclamaram do incômodo com a presença de grupos de trabalhadores nas cachoeiras das comunidades. Com a presença dos "homens estranhos", é comum que os pais e as mães não deixem que crianças e adolescentes saiam sozinhas de suas casas. Uma jovem de 15 anos que havia acabado de se mudar da localidade chamada Água Santa ${ }^{4}$ reclamou dos "homens trabalhando demais na beira da estrada, então a gente ficava assim, com um pouco de medo de sair, porque tinha só homem assim trabalhando" (Entrevista realizada no dia 17 de julho, 2012).

Em nossa experiência no campo de pesquisa, observamos a aflição de grande parte das jovens em relação aos estrangeiros, porém algumas se mostravam animadas com as festas e a presença de pessoas diferentes na região. $\mathrm{O}$ que estas criticavam eram as fofocas desencadeadas pelo envolvimento delas com esses trabalhadores. Era comum que os pais, professores e agentes públicos se manifestassem reprovando as relações afetivas e sexuais entre as jovens da região e os homens de fora. Em parte a reprovação se dava pelas denúncias de violência sexual e também pelo aumento das parturientes. Outro fator que nos parece crucial é que o envolvimento das jovens revelava a atividade sexual delas, aspecto que em cidades pequenas é marcado "por invisibilidade e permeada por mecanismos de silenciamento" (Quadros, 2013, p. 149). A vivência da sexualidade e os problemas provocados rompiam o véu de invisibilidade esperada. Embora tais questões envolvessem a vida das jovens, elas dificilmente eram instadas a se posicionar, a dizer o que pensam e o que gostariam que ocorresse. As tensões nesse campo revelaram um tema espinhoso na medida em que os envolvimentos entre as moças e os trabalhadores desvelavam a complexidade da posição das mulheres naquele cenário (Quadros, 2013). A defesa das "filhas e esposas" contra os homens estranhos legitimava, em muitos casos, a manutenção de práticas machistas que desqualificavam a capacidade de escolha e decisão das mulheres.

A presença dos trabalhadores também aparece na intensa movimentação de veículos pelas estradas até então pouco movimentadas. As possantes camionetes da empresa impressionavam os rapazes do MatoDentro e muitos relatavam o desejo de trabalhar como motoristas para a Anglo American. O interesse dos jovens por essa profissão deriva, em parte, do fato de essa não exigir qualificação profissional. Entretanto, é fundamental considerar o poder simbólico exercido pela empresa sobre os jovens do lugar. A situação profissional na região, com predomínio de atividades agropastoris e alguns empregos no setor de serviços, foi subitamente alterada quando o projeto extrativista surgiu como uma via para a melhoria de vida da população local. A representação da riqueza e do poder da Anglo se faz visível nos trajes dos funcionários da empresa e também nas radiantes camionetes com tração nas quatro rodas que cortam as estradas da região. Esses veículos, que desbravam as poeirentas estradas de terra, são também representativos da modernidade que chega com a instalação do projeto extrativista. No distrito de Itapanhoacanga uma funcionária da escola local contou que "os meninos ficam muito impressionados com os carros, as camionetes, carretas e tal. Ela diz que teve uma vez que pousou helicóptero no campinho e nesse dia os meninos ficaram impossíveis, enquanto não iam ver o helicóptero não sossegavam" (Diário de campo, dia 06 de agosto de 2012). O manejo do imaginário é um recurso utilizado pelo empreendedor que suscita nos sujeitos o desejo pelo novo projeto com seus desígnios e funções, objetos e símbolos.

\section{Os problemas ambientais: dos caminhos aos rios}

A construção do projeto alterou drasticamente o caminho por onde circulam os moradores, em especial nas imediações da Serra da Ferrugem. Os jovens relatam como a degradação dos córregos, a poeira e o barulho os incomodavam em suas vidas cotidianas. Na conversa com três moças que moram nos arredores de São José do Jassém, distrito de Alvorada de Minas, elas contaram dos problemas que tiveram com a água naquela comunidade. Uma delas disse: "vocês lembram quando eu vinha para cá nadar. E ai a água do rio tava toda suja, aí eu enchi de bolinhas [no corpo]" (entrevista realizada no dia 11 de julho de 2012). Nesse mesmo dia, outro rapaz contou "que gosta dos amigos e de jogar bola no fim da tarde, diz que não há nada para reclamar. Em relação aos impactos da mineração ele diz que 'no mais é o rio poluído', reclama que não dá para nadar no rio que fica com coceira" (Diário de campo, dia 11 de julho, 2012).

Um dos problemas ambientais mais preocupantes associados à construção do "Minas-Rio" é a poluição e o assoreamento dos rios da região, considerando que muitas comunidades estão às margens desses rios e dependem deles para suas necessidades diárias. $\mathrm{O}$ 
diretor de uma escola próxima à comunidade chamada Água Quente relata:

Os meninos da Água Quente chegavam aqui dizendo que não tinha água pra beber... porque agora eles colocaram um poço lá ... Eles tiveram que levar água mineral para eles. "Ah, a gente tem que tomar água mineral e mamãe tem que ficar poupando", aquela coisa toda. Vinte litros de água mineral. Pra passar quantos dias? Pra cozinhar, e são famílias numerosas. (Entrevista realizada no dia 11 de julho, 2012)

As ações da Anglo American afetam os rios, as matas e estradas, laços territoriais que unem as comunidades. São os problemas observados no curso das águas e no caminho das pessoas que fornecem elementos para críticas coletivas mais consistentes ao "Minas-Rio"s. No parecer elaborado por uma empresa de consultoria socioambiental, a Diversus (2011, p. 11), vinte e duas comunidades foram reconhecidas como atingidas. Dentre elas, a comunidade da Água Santa também conhecida como Mumbuca - deixou de existir em meados de 2012 com o reassentamento compulsório dos últimos moradores. Esse fato se revelou um aviso para outras localidades que poderiam ter o mesmo destino. $\mathrm{O}$ medo da falta de água é também justificado ao se considerar relatórios técnicos que detalham o problema dos efeitos concomitantes do mineroduto e do rebaixamento do lençol freático sobre o regime hídrico na região (Diversus, 2011; SISEMA, 2008). A angústia provocada pela situação das águas é um fator que une os moradores mais críticos aos que apoiam a mineração. Destarte, mesmo os fervorosos defensores do projeto demonstram preocupação em relação a esse aspecto. Duas jovens entrevistadas que faziam curso técnico em mineração e aguardavam uma oportunidade para trabalhar na Anglo American disseram:

Eles [A Anglo American] acham assim que a água é... é inesgotável, e na verdade a gente já vê, eu tava contando hoje pra ela que a gente foi lá no rio. Tava falando, "aqui, antigamente... que é o tempo de 5,6 anos, por aí, aqui não dava pra passar, porque tudo era água"... Ali também subindo pra Igreja do Rosário, você pode ver um cano, lá... Hoje corre lá um pinguinho de água, a gente tomava banho ali debaixo. Então isso aí, quem tá causando? (Entrevista realizada no dia 27 de outubro, 2012)

Outras queixas em relação ao barulho, à degradação da vegetação e à poeira materializam experiências negativas dos moradores com os efeitos ambientais perpetrados pelo projeto. Todos esses problemas afetam mais aqueles que moram na área de entorno da mina.

A intensa presença de pessoas estranhas no MatoDentro, os impactos ambientais e a degradação dos rios revelam aspectos negativos do projeto "MinasRio". No entanto, ao escutar o que os jovens dizem, ao colocá-los para debater a mineração, vemos que há outros elementos percebidos como positivos sobre a presença da mineradora na região.

\section{Emprego e futuro: as expectativas de desenvolvi- mento}

Quando os muitos jovens com os quais interagimos no campo de pesquisa eram perguntados sobre o que pensavam da mineração, a maioria dizia que achava "bom" a Anglo ter chegado porque agora havia emprego. É assim que uma jovem de 14 anos nos contou "que antes o pessoal não tinha trabalho e hoje tem. Diz que tem muitas pessoas próximas trabalhando nas firmas e empresas, como seu pai e seu primo" (Diário de campo referente ao dia 11 de julho de 2012). Os empregos necessários para a realização do projeto, sobretudo os que exigem pouca qualificação formal, são ocupados preferencialmente por moradores da região. Já os cargos que exigem curso superior são quase todos preenchidos por pessoas de fora da região, com a justificativa de que a falta de qualificação impede a contratação de moradores do MatoDentro. Tal situação alimenta tanto a crítica à empresa como suscita o desejo de qualificação profissional por parte dos habitantes locais. Por essa razão, parte dos jovens do MatoDentro buscam se qualificar para ocupar melhores cargos na mineradora. Qual curso técnico é mais valorizado pela mineração? Quais procedimentos os jovens devem adotar para entrar na Anglo? São perguntas recorrentes quando conversamos com os jovens de CMD, Alvorada de Minas e Dom Joaquim. Como argumenta uma jovem entrevistada em CMD: "Todo mundo hoje, tendo escolaridade ou não, tem emprego. Mesmo que seja braçal, mesmo que seja pesado. Eagora quem tá no braçal, quem tá no pesado, tá tentando se desenvolver cada vez mais" (entrevista realizada em CMD em 07 de julho de 2012). A demanda por profissionais de nível técnico e superior na região intensificou a busca, difícil e distante para os jovens oriundos do meio rural, por cursos técnicos e faculdades (Paulo, 2013).

Em CMD é comum escutar pelas ruas da cidade que em "Conceição, só não trabalha quem não quer". A oferta de emprego e o aumento de renda mostram a força do "Minas-Rio" como agente ordenador das relações sociais deslocadas na região. Ainda que os moradores convivam com tantos problemas em suas vidas cotidianas, a demarcação de que a Anglo American é a responsável pelos empregos aparece como irredutível recurso de apoio, acionado quando alguma crítica se impõe como rechaço estrutural à 
presença da mineradora na cidade. Ao analisar outras experiências de instalação de grandes projetos de mineração, observamos que tal recurso, a ênfase na oferta de emprego como modo de conseguir apoio da população local, é comum entre diferentes projetos extrativistas (Coelho, 2015; Zhouri \& Laschefski, 2010). Para um jovem do $3^{\circ}$ ano da Escola Estadual Mestre Sebastião Jorge em CMD:

Antes não tinha nada. Igual eu vejo muita gente falando: "ah a Anglo veio destruir a terra da gente"... Nem tinha renda a pessoa, se todo mundo tivesse ganhando o dinheiro que eles tão ganhando, ninguém tava reclamando de nada, vem emprego. “Vai prejudicar algumas coisas?” Sim... o ar vai... mas vai ficar bom, já estão construindo outra escola lá pra gente, entendeu, então a gente não precisa ir embora. (Transcrição de roda de conversa, dia 8 de novembro, 2012)

Ainda que suas palavras sejam titubeantes, sua posição é afirmativa a respeito do problema em sua vida para o qual a mineração foi uma resposta. $\mathrm{O}$ rapaz diz que "antes não tinha nada" e agora, com a chegada da Anglo, "a gente não precisa tá indo embora". Em sua narrativa, o jovem contrapõe o presente de possibilidade ao passado marcado pelas dificuldades financeiras e pela necessidade de migração. A memória recente da contínua migração dos jovens da região para os centros maiores nos revela um aspecto que influi decisivamente no juízo dos moradores sobre o novo projeto mineral. Historicamente na região, enquanto os filhos da elite local migravam para realizar o ensino médio e ingressar nas boas faculdades do estado, os filhos das classes trabalhadoras migravam para ocupar as vagas no setor industrial ou de serviços da região metropolitana de Belo Horizonte. A instalação de uma unidade do Serviço Nacional de Aprendizagem Industrial (Senai) em CMD - condicionante estabelecida no licenciamento ambiental - materializa as expectativas do jovens de acesso às benesses do desenvolvimento. O objetivo central do Senai é formar profissionais para trabalhar na fase de operação da mina. Durante o curso, os alunos, em sua maioria formada por jovens com menos de 29 anos, recebem uma bolsa de estudos para se dedicarem integralmente à formação profissional. Há intensa disputa entre os moradores da região por essa possibilidade, e era comum escutar críticas aos procedimentos de escolha dos estudantes. Em trecho de um jornal da Anglo American destinado à população atingida pela mineração, percebe-se a relevância do Senai para a mineradora :

Sérgio Henrique Teixeira, de 27 anos, ainda nem concluiu o curso de Mecânico de Instalações Industriais, oferecido pelo SENAI-Conceição do
Mato Dentro em parceria com a Anglo American, mas já pensa no que fazer em seguida. "Não quero apenas me formar, o importante é aprender. Meu objetivo é adquirir o máximo de conhecimento e, no futuro, fazer um curso de engenharia", planeja. Outra meta do estudante é conquistar uma vaga na Anglo American. "Estou fazendo de tudo para entrar na empresa. Sempre sonhei em estar na minha cidade fazendo o que gosto, e agora estou tendo essa oportunidade", afirma. (Transformação real, 2012)

A formação profissional articula educação e trabalho e, mais do que a oferta direta e temporária de emprego, sedimenta em grande parte da população a perspectiva de um futuro melhor alicerçado no projeto "Minas-Rio". Por estarem no momento de entrada no mercado de trabalho formal - lembrando que muitos deles já trabalham de forma informal -, os jovens de CMD passaram a ser atores estratégicos no investimento simbólico da multinacional.

\section{Considerações finais}

O contraste narrado entre o passado do MatoDentro e o presente agenciado pela Anglo American, antes de revelar um dado objetivo, é um efeito de um processo político. Para se mostrar capaz de ordenar um campo social fraturado, cujos alicerces foram deslocados pela imposição do projeto extrativista, a empresa precisou se mostrar relevante para ditar os rumos e o destino do território.

Dessa forma, a expectativa de permanência dos jovens na cidade, baseada em um trabalho qualificado, se impõe como uma resposta para a erradicação da migração e de fortalecimento da sociedade local. Esta formulação, imbricada no imaginário do progresso e desenvolvimento, põe em curso modelos de como os jovem devem viver, quais escolhas devem fazer e o que devem desejar. Com isso vemos o maior poder que a Anglo American exerce sobre a região: sua capacidade de definir os caminhos materiais e simbólicos, de definir os modos de perceber o mundo, agir e querer. Pois, apesar dos tantos e graves problemas denunciados em relação à devastação ambiental, aos problemas sociais, ao desrespeito às práticas coletivas e à história das comunidades, a formação profissional, o emprego e a promessa de desenvolvimento parecem responder, parcialmente, aos deslocamentos gerados pelo empreendimento.

O "Minas-Rio" é o resultado da negociação entre grandes empresas com o Estado de Minas Gerais que, independente da vontade das comunidades locais, decidiram uma nova função para o território do MatoDentro. O projeto foi e continua a ser - para 
muitos - reverenciado como uma saída para a "pobreza” da região. No entanto, problemas de diferentes ordens se arrastam desde as primeiras movimentações, colocando o empreendimento em questão. Refletir pela experiência dos jovens é considerar os juízos singulares daqueles que vivem no território, interrompendo um movimento de apreciação genérica sobre a mineração. Assim, trata-se de analisar o projeto por suas práticas e efeitos: os carros "das firmas", os novos cursos e empregos, as pessoas de fora, a falta de água, a modificação dos caminhos rurais, a degradação de rios. A complexidade da situação não facilita a vida de quem quer uma resposta simples, de quem quer ver o novo ciclo de mineração como dádiva ou danação.

O que nos interessava não era a versão ditada pela empresa sobre os jovens do MatoDentro, mas como aqueles jovens sentiam e simbolizavam o processo em curso. Entendemos que as formulações contrárias ou favoráveis ao empreendimento não se somam nem se anulam, cada posição com suas contradições revela modos de subjetivação em curso na região. Assim, analisamos o que os jovens contavam, sem buscar uma posição absoluta - logo distanciada - sobre o "Minas-Rio". Desta feita, a afirmação categórica de uma jovem de CMD de que a presença das empresas na região permitiu às jovens do lugar possibilidades de educação e trabalho não responde ao sofrimento cotidiano de pessoas que perderam seus meios de vida e que vivem angustiadas com a possibilidade do fim de suas localidades. Por sua vez, a violência da exploração do minério não elimina do cenário a expectativa daqueles que apoiam o empreendimento e que acreditam na proposta de desenvolvimento.

$\mathrm{O}$ que se revela crucial, antes de medir e pesar as situações e, assim, escolher uma posição, é permitir que as vozes dos sujeitos reverberem no cenário em conflito. Que as palavras dos jovens e seus múltiplos sentidos rompam o silenciamento imposto sobre eles, sobretudo por aqueles que afirmam saber o que seria melhor ou pior para eles sem que lhes seja permitido expressar o que vivem, pensam e o que querem para suas vidas e para suas comunidades.

\section{Notas}

1 A Anglo American é uma empresa criada na África do Sul em 1917 com sede em Londres, Inglaterra. Para informações a respeito da empresa, ver: http://www.angloamerican.com/ about-us/history. Neste artigo analisamos a situação na mina, sem abordar as questões que envolvem as outras estruturas do projeto. Para a discussão da situação na construção do mineroduto e do Porto de Açu, ver AGB (2011).

2 Com o objetivo de enfatizar o território afetado pelo empreendimento e seguindo a proposição de Becker (2009, p. 243), designamos por "MatoDentro" a região próxima à mina, englobando cidades, distritos e comunidades rurais nas imediações da Serra da Ferrugem.

3 Nos anos 2000 uma articulação entre sociedade civil e poder público de CMD definiu o turismo como eixo econômico da cidade, que passou a ser chamada de "capital mineira do ecoturismo" (Becker, 2009). Com o projeto da Anglo American houve uma substituição do turismo pelo extrativismo como eixo econômico (Becker, 2009; Fazito, 2013).

4 Segundo a população local, as águas que correm na localidade teriam propriedades curativas, por isso o nome de "Água Santa".

5 Para uma compreensão do processo político e da luta dos atingidos, ver Diversus (2011); Becker (2009, pp. 323367) e também a página na internet da Coordenadoria de Inclusão e Mobilizações Sociais (CIMOS) do MPE: http:// cimos.blog.br/reasa/conceicao-do-mato-dentro-e-regiao/

\section{Referências}

Acselrad, H. (2004). As práticas espaciais e o campo dos conflitos ambientais. In Conflitos Ambientais no Brasil (pp. 23-35). Rio de Janeiro: Relume Dumará

Alvaro, J. L. \& Garrido, A. (2006). Psicologia Social perspectivas psicológicas e sociológicas. São Paulo: McGraw-Hill.

Associação dos Geógrafos Brasileiros - AGB. (2011). Relatório dos impactos socioambientais do Complexo Portuário do Açu. Rio de Janeiro. Acesso em 23 de janeiro, 2014, em http://www.agb.org.br/documentos/Relatorio_dos Impactos\%20socioambientais do Complexo_Portuario do_Acu_AGB_14092011.pdf

Bacelar, R. P. (2014). Nem só de mineração vive o MatoDentro: a experiência de jovens em território de conflito socioambiental. Tese de doutorado, Programa de Pósgraduação em Psicologia, Universidade Federal do Rio de Janeiro, Rio de Janeiro.

Becker, L. (2009). Tradição e modernidade: o desafio da sustentabilidade do desenvolvimento na Estrada Real. Tese de Doutorado, Programa de Pós-graduação em Ciência Política, Instituto Universitário de Pesquisas do Rio de Janeiro, RJ.

Becker, L. C. \& Pereira, D. C (2011). O projeto Minas-Rio e o desafio do desenvolvimento territorial integrado e sustentável: a grande mina em Conceição do Mato Dentro. In F. R. C. Fernandes, M. A. R. S. Enríques, \& R. Alamino (Orgs.), Recursos minerais e sustentabilidade territorial: grandes minas (pp. 229-258). Rio de Janeiro: CETEM/ MCTI.

Castro, L. R. (2001a). Da invisibilidade à ação: crianças e jovens na construção da cultura. In Crianças e jovens na construção da cultura (pp. 19-46). Rio de Janeiro: NAU/FAPERJ.

Castro, L. R. (2001b). Crianças, jovens e cidades: vicissitudes da convivência, destinos da cidadania. In Subjetividade e cidadania - um estudo com crianças e jovens em três cidades brasileiras (pp. 113-156). Rio de Janeiro: 7 letras.

Castro, L. R. (2011). Os jovens podem falar? Sobre as possibilidades políticas de ser jovem hoje. In M. I. Moreira, J. Dayrrell, \& M. Stengel (Orgs.), Juventudes contemporâneas: um mosaico de possibilidades (pp. 299324). Belo Horizonte: Puc Minas. 
Coelho, T. P. (2015). Projeto Grande Carajás - trinta anos de desenvolvimento frustrado. Marabá, PA: Editorial Iguana.

Diversus. (2011). Diagnóstico socioeconômico da área diretamente afetada e da área de influência direta do empreendimento Anglo Ferrous Minas- Rio Mineração. Acesso em 22 de janeiro, 2014, em http://www.diversus.net. br/cmd/diagnostico ada e ae.pdf

Fazito, M. R. F. (2013). Competing Rationalities of Tourism Development in the Espinhaço Range Biosphere Reserve, Brazil. Tese de Doutorado, Programa de Pós-graduação em Geografia, Planejamento e Política Ambiental, University College Dublin, Dublin.

Galdino, R. (2013, 27 de novembro). Obras de mineroduto devastam Conceição do Mato Dentro. Jornal Hoje em dia. Acesso em 24 de janeiro, 2014, em http://www.hojeemdia. com.br/horizontes/obras-de-mineroduto-devastam-conceico-do-mato-dentro-1.196318

Geertz, C. (2012). O saber local: novos ensaios em antropologia interpretativa (12 ${ }^{\mathrm{a}}$ ed.). Petrópolis, RJ: Vozes.

Goldman, M. (2006). Alteridade e experiência: antropologia e teoria etnográfica. Etnográfica, 10(1), 161-173.

Glynos, J. \& Howarth, D. (2007). Logics of critical explanation in social and political theory. Abingdon, UK: Routeledge.

Ibase \& Polis. (2007). Juventude e integração Sul-Americana: caracterização de situações tipo e organizações juvenis. Rio de Janeiro: Autores. Acesso em 23 de janeiro, 2014, em http://forumeja.org.br/files/brasil.pdf

Jerônimo, R. N. T. \& Souza, R. V. C. (2015). Psicologia ambiental: um estudo acerca da resistência frente à mineração em Içara, SC. Psicologia \& Sociedade, 27(1), 80-86.

Laclau. E. (1993) Nuevas reflexiones sobre la revolución de nuestro tiempo. Buenos Aires: Nueva Visión.

Mataresi, A. (2012). Histórias que o rio traz - reflexões sobre o enraizamento em uma comunidade ribeirinha da Amazônia. Dissertação de Mestrado, Programa de Pós-graduação em Psicologia Social e do Trabalho, Universidade de São Paulo, SP.

Mattos, A. R. (2011). Liberdade, um problema do nosso tempo: os sentidos da liberdade para jovens no contemporâneo. Tese de Doutorado, Programa de Pós-graduação em Psicologia, Universidade Federal do Rio de Janeiro, RJ.

Minayo, M. C. S. (2012). Análise qualitativa: teorias, passos e fidedgnidade. Ciência \& Saúde Coletiva, 17(3), 621-626.

Narita, S. (2006). Notas de pesquisa de campo em Psicologia Social. Psicologia \& Sociedade, 18(2), 25-31.

Norval, A. (2007). Aversive democracy - Inheritance and originality in the democratic tradition. New York: Cambridge University Press.

Paulo, M. A. L. (2013). Juventudes rurais nos pequenos municípios do Nordeste do Brasil. Uma breve reflexão acerca do desenvolvimento rural. In J. A. Meneses, M. R. Costa, \& T. C. S. Araujo (Orgs), Territórios interculturais de juventude (pp. 325-341). Recife: UFPE.

Pedrosa, A. P., Grossi, P., \& Ariadne, Q. (2013, 28 de julho). Os órfãos do progresso. $O$ Tempo. Acesso em 20 de janeiro, 2014, em http://www.otempo.com.br/capa/economia/os$\% \mathrm{C} 3 \% \mathrm{~B} 3 \mathrm{rf} \% \mathrm{C} 3 \% \mathrm{~A} 3$ os-do-progresso-1.687873

Peirano, M. A. (1995). A favor da etnografia. Rio de Janeiro: Relume-Dumará.

Quadros, M. T. (2013). Sexualidade de mulheres jovens urbanas e rurais: algumas notas sobre autonomia e processos de invisibilização nos serviços de saúde. In J. A. Meneses, M. R. Costa, \& T. C. S. Araujo (Orgs.), Territórios Interculturais de Juventude (pp. 131-152). Recife: UFPE.

Rancière, J. (1996). O desentendimento. São Paulo: Editora 34. Rattansi, A. \& Phoenix, A. (1997). Rethinking Youth Identities: modernist and postmodernist frameworks. In J. Bynner, L. Chisholm, \& A. Furlong (Orgs.), Youth, Citizenship and Social Change in a European Context (pp. 121-149). Aldershot, UK: Ashgate. Rezende, J. (2013, 19 de novembro). Força-tarefa resgata haitianos em trabalho degradante em MG. O Tempo, p. 10. Acesso em 13 de dezembro, 2013, em http://www.otempo.com.br/for\%C3\%A7a-tarefa-resgatahaitianos-em-trabalho-degradante-em-mg-1.748146

Sato, L. \& Souza, M. P. S. (2001). Contribuindo para desvelar a complexidade do cotidiano através da pesquisa etnográfica em psicologia. Psicologia, 12(2), 29-47.

Sistema Estadual de Meio Ambiente - SISEMA. (2008). Parecer Único SISEMA $N^{\circ} 001 / 2008$. Belo Horizonte: Autor. Acesso em 13 de dezembro, 2013, em file:///C:/Users/Usuario/ ownloads/4.1_-00472_2007_001_2007_Anglo_Ferrous Minas-Rio Minera\%C3\%A7\%C3\%A3o S.A. - - PU.pdf

Transformação real. (2012). Editorial. Diálogo - Publicação destinada às comunidades de relacionamento da Anglo American, 3(15), Mar/abr/maio. Acesso em 18 de janeiro, 2014, em http://brasil.angloamerican.com/ /media/Files/A/ Anglo-American-Brazil/Attachments/pdf/dialogo-minabeneficiamento/dialogo-mina-beneficiamento-15mai12.pdf

Zhouri, A. \& Laschefski, K. (2010). Desenvolvimento e conflitos ambientais: um novo campo de investigação. In Desenvolvimento e conflitos ambientais (pp. 11-31). Belo Horizonte: UFMG.

\section{Agradecimento}

Ao CNPq, pelo apoio (Processo no. $141397 / 2010-$ 1 , bolsa de doutorado).

Submissão em: 22/04/2015

Revisão em: 30/08/2015

Aceite em: 24/10/2015

Rafael Prosdocimi Bacelar é doutor em Psicologia pelo Programa de Pós-graduação em Psicologia na Universidade Federal do Rio de Janeiro. Atualmente leciona no curso de Psicologia da Faculdade Pitágoras de Betim/MG, e no Centro Universitário UNA em Belo Horizonte e em Contagem, MG.

Endereço: Rua do Ouro, 1344/207, Serra. Belo Horizonte/ MG,Brasil. CEP 30220-000 E-mail: rafaelpros@gmail.com

Lucia Rabello de Castro é doutora em Psicologia pela Universidade de Londres, Grã-Bretanha. Atualmente é professora Titular do Instituto de Psicologia da Universidade Federal do Rio de Janeiro, e professora do Programa de Pós-graduação em Psicologia desse Instituto. E-mail: 1rcastro@infolink.com.br 